\title{
https://doi.org/10.36470/famen.2020.14c16 \\ OS INSTITUTOS FEDERAIS E O DIREITO À EDUCAÇÃO ESPECIAL NO ENSINO SUPERIOR
}

\author{
Andrezza M. B. do N. Tavares ${ }^{1}$ \\ Breno Trajano de Almeida ${ }^{2}$
}

\section{RESUMO}

A configuração da educação especial no ensino superior é direcionada à perspectiva inclusiva. Este trabalho atentou para um estudo exploratório e descritivo dos Planos de Desenvolvimento Institucional dos Institutos Federais de Educação, Ciência e Tecnologia na perspectiva do direito à educação para pessoas com deficiência, incluindo análise das ações relativas à diferenciação curricular e condições de acessibilidade física, pedagógica, estrutural e de materiais/recursos, possibilitando agregar informações importantes e significativas sobre inclusão dos estudantes com deficiência. A partir das análises foi possível depreender que, apesar dos avanços na consignação da Educação Especial como direito e modalidade específica, muitas das suas indispensáveis adequações ainda configuram como intencionalidade, especialmente no ensino superior.

Palavras-chave: Educação Especial. Institutos Federais. Inclusão. Ensino Superior.

\section{INTRODUÇÃO}

É na Idade Moderna que começam os primeiros métodos de comunicação e educação para pessoas surdas, contrariando o senso comum da época de que essas pessoas não podiam ser escolarizadas. No século XIX, surge a escrita Braille, que permite a escolarização de cegos. É também o período em que as primeiras percepções sobre as necessidades das pessoas com deficiência passam a ser reconhecidas e analisadas no mundo todo.

No século XX, a humanidade assolada por diversas guerras, sendo duas mundiais, se viu impelida não apenas a reconstruir-se, como a tratar, reabilitar e incluir os milhares de feridos e mutilados, surgindo então, entidades voltadas às pessoas com deficiência. De acordo com Marcelino (2013), em 1962 inicia-se nos Estados Unidos o movimento pelos direitos das pessoas com deficiência, com a criação do $1^{\circ}$ Centro de Vida Independente no Mundo.

Para SASSAKI (1999, p.41), a inclusão é "um processo pelo qual a sociedade se adapta para poder incluir em seus sistemas sociais gerais", capacitando a pessoa com deficiência para assumir seus papéis na sociedade.

\section{A EDUCAÇÃO ESPECIAL NO BRASIL}

No Brasil, segundo Mazzotta (2005, p.28-29), o Imperador Dom Pedro II (1840-1889), criou o Imperial Instituto dos Meninos Cegos, atualmente Instituto Benjamin Constant, por meio

\footnotetext{
${ }^{1}$ Doutora em Educação pela Universidade Federal do Rio Grande do Norte. E-mail: andrezza.tavares@ifrn.edu.br ${ }^{2}$ Mestre em Educação pela Universidade de São Paulo (USP). E-mail: breno.almeida@ifrn.edu.br
} 
do Decreto Imperial n ${ }^{\circ}$ 1.428, de 12 de Setembro de 1854 e, em 26 de setembro de 1857, fundou o Imperial Instituto de Surdos Mudos, atualmente Instituto Nacional de Educação de Surdos INES. Mas, somente em 1890, no primeiro Censo da República, é que são incluídas informações sobre deficiência, ao pesquisar por: nome, sexo, idade, estado civil, cor, filiação, naturalidade, nacionalidade dos pais, defeitos físicos e residência (IBGE 2003).

A Lei Brasileira de Inclusão da Pessoa com Deficiência (Estatuto da Pessoa com Deficiência-PCD), Lei $\mathrm{n}^{\circ}$ 13.146, de 06 de julho de 2015, indicou quais direitos deveriam ser garantidos às pessoas com deficiência de modo geral e aos estudantes com deficiência e com altas habilidades. Cabe destacar que a Lei incluiu as instituições privadas de ensino nessa obrigatoriedade (art. 28, parágrafo $1^{\circ}$ ), encerrando de uma vez por todas as possibilidades de negar matrícula a pessoa com deficiência, sob o argumento de que a obrigatoriedade era só das escolas públicas.

Com a substituição da Política Nacional de Educação Especial pela Política Nacional de Educação Especial na Perspectiva da Educação Inclusiva (2008), o objetivo passou a ser a inclusão escolar de alunos com deficiência, transtornos globais do desenvolvimento e altas habilidades/superdotação da Educação Infantil ao ensino Superior.

O Censo INEP 2018 registra que 1.224.909 pessoas com deficiências estão matriculadas desde a Educação Infantil até o Ensino Superior, sendo que 1.181.276 estudantes em escolas de educação básica ${ }^{3}$ e, 43.633 na educação superior ${ }^{4}$. O Gráfico 1 mostra a evolução das matrículas especificamente neste último nível de ensino, foco dessa pesquisa:

Gráfico 1: Evolução das matrículas de alunos com deficiência no ensino superior.

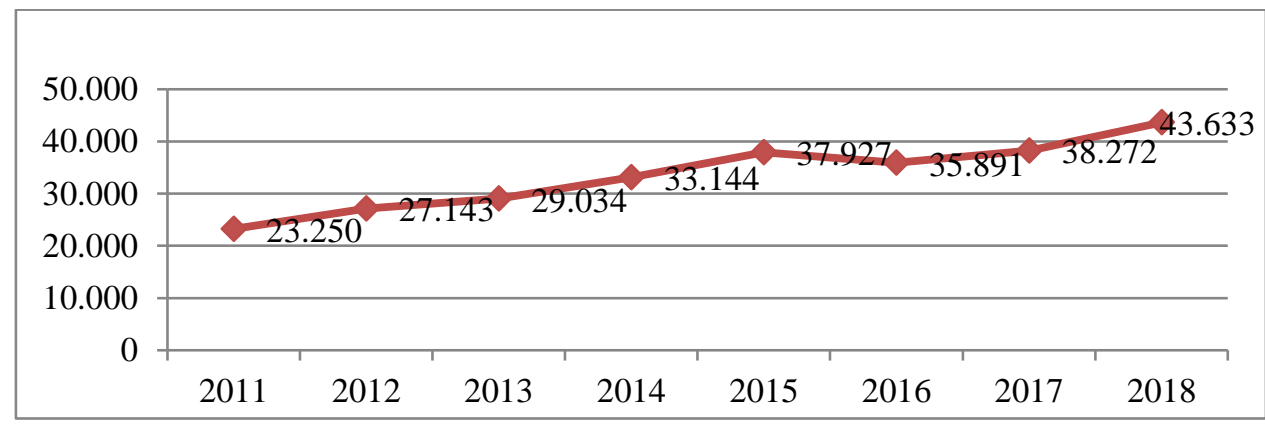

Fonte: INEP/2018

Na educação básica, o total das matrículas se dá, predominantemente, em escolas públicas: $992.084(83,9 \%)$ contra $188.192(16 \%)$ em escolas privadas. Essa distribuição é invertida no

\footnotetext{
${ }^{3}$ http://portal.inep.gov.br/web/guest/sinopses-estatisticas-da-educacao-basica

${ }^{4}$ http://portal.inep.gov.br/web/guest/sinopses-estatisticas-da-educacao-superior
} 
Ensino Superior, no qual predominam as matrículas em instituições privadas: $27.048(61,9 \%)$ para 16.585 (38\%) em instituições públicas.

É relevante, nesse contexto, destacar que a distinção de matrículas de pessoas com deficiência no ensino superior, só foi incluída, no Censo/Inep, a partir de 2011, sendo que, nesses 07 anos, o crescimento desse segmento, ultrapassou 40\% de matrículas, de 23.250 em 2011 para 43.633 em 2018, de acordo com o Censo da Educação Superior, MEC/INEP/2011 - 2018.

O Censo da Educação Superior não elenca a instituição ofertante, apenas a Rede de Ensino, então, é importante que haja uma contextualização que também pode ser um alerta para que o Censo do Ensino Superior discrimine as instituições ofertantes em cada Unidade de Federação. Merecem registros algumas situações sobre a distribuição das matrículas da Educação Especial no Ensino Superior, conforme o Censo/Inep/2018:

- Nas regiões Norte e Nordeste, nas matrículas totais, predominam as instituições públicas (61,7\%), embora Rondônia, Amazonas e Amapá, no Norte e Bahia, no Nordeste tenham números maiores nos estabelecimentos privados.

- Nas regiões Sudeste, Sul e Centro-Oeste, a grande maioria das matrículas está na esfera privada de ensino superior - 72,8\% ou, 21.797 das 29.915 matrículas registradas, somando-se as três regiões. Na região Sul, o Paraná tem o menor número de matrículas (176) em estabelecimentos federais de educação superior, ficando atrás apenas de Roraima (144) e Amapá (88) em âmbito nacional. O Mato Grosso do Sul é o único estado, fora do eixo Norte/Nordeste a ter maior número de matrículas públicas.

\section{OS INSTITUTOS FEDERAIS E A EDUCAÇÃO ESPECIAL}

Em 29 de dezembro de 2008, com a sanção da Lei $N^{\circ}$ 11.892/08, que instituiu a Rede Federal, 31 Centros Federais de Educação Tecnológica (CEFETs), 75 Unidades Descentralizadas de Ensino (UNEDs), 39 Escolas Agrotécnicas, 07 Escolas Técnicas Federais e 08 escolas vinculadas a universidades deixaram de existir para formar os Institutos Federais de Educação, Ciência e Tecnologia.

Atualmente, existem 38 Institutos Federais de Educação - IF, mais o Colégio Pedro II ${ }^{5}$, que juntos somam um total de 611 campi, distribuídos em todos os estados brasileiros.

Com essa expansão, os Institutos Federais tiveram que criar suas normas internas, apresentando o perfil da instituição, suas atividades de ensino, pesquisa e extensão, oferecendo

\footnotetext{
${ }^{5}$ Integrado à Rede Federal de Educação Profissional, Científica e Tecnológica nos termos da Lei no 11.892 , de 29 de dezembro de 2008, com a redação dada pela Lei n ${ }^{\circ} 12.677$, de 25 de junho de 2012. Para efeito de incidência das disposições normativas acerca da regulação, da avaliação e da supervisão da instituição e dos cursos de educação superior, o CPII é equiparado aos Institutos Federais (PDI, p.24)
} 
uma visão de presente e futuro (Muriel, 2006), incluídas as demandas relativas "às diferentes modalidades de ensino" (art. $2^{\circ}$ da Lei) exigindo, portanto, uma ressignificação do potencial formativo dos Institutos.

Essa ressignificação, minimamente, deverá estar configurada no Plano de Desenvolvimento Institucional - PDI, elaborado autonomamente por cada Instituto, de caráter plurianual e publicado por Resolução aprovada no respectivo Conselho Superior.

Para Rocha (2016), as iniciativas individualizadas de cada instituto deixam evidente a falta de uma institucionalidade nas ações voltadas à oferta de educação especial a ao atendimento das especificidades dos estudantes.

É, portanto, no PDI que se dá a continuidade da pesquisa sobre a Educação Especial nos IFs, iniciando pelo período de vigência, cujo resultado pode ser configurado em quatro situações: Sem Informação; Aprovado (pelo respectivo Conselho); Em Construção e em Consulta Pública, conforme Quadro 1:

Quadro 1: Levantamento da vigência/situação dos Planos de Desenvolvimento Institucional dos Institutos Federais de Educação.

\begin{tabular}{|c|c|c|c|}
\hline Região & Instituto Federal & Vigência Definida & Situação \\
\hline \multirow[t]{7}{*}{$\mathrm{NO}$} & IF do Acre - IFAC & 2014-2018 & Sem Informação \\
\hline & IF do Amazonas - IFAM & $2019-2023$ & Consulta Pública \\
\hline & IF do Amapá - IFAP & $2019-2023$ & Aprovado \\
\hline & IF do Pará- IFPA & $2019-2023$ & Em Construção \\
\hline & IF de Rondônia - IFRO & $2018-2022$ & Aprovado \\
\hline & IF de Roraima - IFRR & $2019-2023$ & Aprovado \\
\hline & IF de Tocantins - IFTO & $2020-2024$ & Em Construção \\
\hline \multirow[t]{11}{*}{$\mathrm{NE}$} & IF de Alagoas - IFAL & $2019-2023$ & Aprovado \\
\hline & IF da Bahia - IFBA & $2015-2019$ & Sem Informação \\
\hline & IF Baiano - IF Baiano & $2020-2024$ & Em Construção \\
\hline & IF do Ceará - IFCE & $2019-2023$ & Em Construção \\
\hline & IF do Maranhão - IFMA & $2019-2023$ & Em Construção \\
\hline & IF da Paraíba - IFPB & $2020-2024$ & Em Construção \\
\hline & IF de Pernambuco - IFPE & 2014-2018 & Sem Informação \\
\hline & IF do Sertão Pernambucano - IF Sertão & $2019-2023$ & Aprovado \\
\hline & IF do Piauí - IFPI & $2020-2024$ & Em Construção \\
\hline & IF do Rio Grande do Norte - IFRN & $2019-2023$ & Em Construção \\
\hline & IF de Sergipe - IFSE & $2020-2024$ & Em Construção \\
\hline \multirow[t]{4}{*}{$\mathrm{SE}$} & IF do Espírito Santo - IFES & 2014-2019 & Sem Informação \\
\hline & IF de Minas Gerais - IFMG & $2019-2023$ & Aprovado \\
\hline & IF do Triângulo Mineiro - IFTM & $2019-2023$ & Aprovado \\
\hline & IF do Norte de Minas - IF Norte Minas & $2019-2023$ & Aprovado \\
\hline
\end{tabular}




\begin{tabular}{|c|c|c|c|}
\hline & IF do Sul de Minas - IF Sul Minas & $2019-2023$ & Aprovado \\
\hline & IF do Sudeste de Minas - IF Sudeste & $2020-2024$ & Em Construção \\
\hline & IF do Rio de Janeiro - IFRJ & $2014-2018$ & Sem Informação \\
\hline & IF Fluminense - IFF & $2018-2022$ & Aprovado \\
\hline & Colégio Pedro II - CPII & $2019-2023$ & Aprovado \\
\hline & IF de São Paulo & $2019-2023$ & Aprovado \\
\hline $\mathrm{S}$ & IF do Paraná & $2019-2023$ & Aprovado \\
\hline & IF do Rio Grande do Sul - IFRGS & $2019-2023$ & Aprovado \\
\hline & IF Sul Rio-grandense - IFSul & $2020-2024$ & Consulta Pública \\
\hline & IF Farroupilha - IFFar & $2019-2026$ & Aprovado \\
\hline & IF de Santa Catarina - IFSC & $2020-2024$ & Consulta Pública \\
\hline & IF Catarinense - IFC & $2019-2023$ & Aprovado \\
\hline $\mathrm{CO}$ & IF de Brasília - IFB & $2019-2023$ & Aprovado \\
\hline & IF de Goiás - IFG & $2019-2023$ & Aprovado \\
\hline & IF Goiano - IF Goiano & $2019-2023$ & Aprovado \\
\hline & IF do Mato Grosso do Sul - IFMS & $2019-2023$ & Aprovado \\
\hline & IF do Mato Grosso - IFMT & $2019-2023$ & Aprovado \\
\hline
\end{tabular}

Fonte: Site de cada Instituto Federal, consultado pelos autores entre fev./mar. 2020.

A sistematização do levantamento considerou a organização regional no intuito de facilitar a visualização, bem como para contextualizar as regiões em função das escolhas que serão feitas, para analisar a situação da Educação Especial nos Institutos Federais.

A primeira incursão se deu nos sumários dos Planos de Desenvolvimento Institucional, visando localizar onde foi inserida a Educação Especial, enquanto modalidade de ensino e, para nossa surpresa, em nenhum PDI há essa discriminação, embora a história da inclusão das pessoas com deficiência nos IFs tenha começado a ser escrita de forma efetiva com a criação do programa TECNEP (2000), que propunha o atendimento das pessoas com deficiência e outras necessidades educativas especiais, na Rede de Educação Tecnológica (SANTOS, 2011, p. 57).

Com esse contexto em mente, passamos à seleção de 05 Planos, entre os que já estão com aprovação do respectivo Conselho Superior, por região, levando em conta: a) o maior número de alunos com deficiência matriculados, no Estado $^{6}$, nas Instituições Federais ${ }^{7}$, conforme dados disponibilizados pelo INEP quanto ao Censo Escolar de 2018 e/ou, b) alguma especificidade que destaque aquele IF dos demais, quando o Estado tiver mais de um Instituto com PDI aprovado.

Dessa forma, na Região Norte, teríamos Amapá com 88 matrículas, Roraima com 144 e Rondônia com 201. No Nordeste, Alagoas com 745 e Pernambuco com 350 matrículas. Sudeste,

\footnotetext{
${ }^{6}$ O Censo não especifica a Instituição.

${ }^{7}$ Esse recorte se deve ao fato de que nem todos os Estados possuem Instituições estaduais e/ou municipais de Ensino Superior.
} 
Minas tem 1.231 matrículas, Rio de Janeiro com 443 e São Paulo, 530. Na Região Sul, Paraná tem 170, Rio Grande do Sul, 995 e Santa Catarina, 331 matriculados. No Centro-Oeste, o Distrito Federal soma 209 matrículas, Goiás, 394, Mato Grosso do Sul, 581 e Mato Grosso, 233.

Nas Regiões Norte, Nordeste e Centro-Oeste as escolhas foram simplificadas pelo número de matrículas em estados com um único Instituto, destacando, para análise, o IFRO, IFAL e IFMS, respectivamente. Na Região Sudeste, optamos por analisar o PDI do Colégio Pedro II por ser a única instituição federal que oferta desde a Educação Infantil (e que está construindo um NAPNE ${ }^{8}$ específico para esse segmento), até a pós-graduação. Na Região Sul, a escolha recaiu no Rio Grande do Sul, que tem o maior número de matrículas e, no IFFAR que, diferentemente dos demais Institutos, tem um PDI para 08 anos.

\section{ANÁLISE DOS PLANOS DE DESENVOLVIMENTO INSTITUCIONAL SELECIONADOS POR REGIÃO.}

\section{Norte: Instituto Federal de Rondônia - IFRO ${ }^{9}$}

O IFRO é resultado da integração, em 2008, da Escola Técnica Federal de Rondônia, à época em fase de implantação, e da Escola Agrotécnica Federal de Colorado do Oeste, originando uma Reitoria, e a previsão de 5 campi. Atualmente, o Instituto Federal de Rondônia possui 09 (nove) campi presenciais, em municípios estratégicos do estado, além de 199 polos de EaD, 23 em parceria com os 22 municípios do Estado e 176 em parceria com o Governo do Estado de Rondônia.

A primeira referência a pessoas com necessidades especiais no PDI do Instituto está na inclusão de "Fortalecimento dos Núcleos de Atendimento às Pessoas com Necessidades Específicas" (NAPNE), no portfólio de Projetos. Na parte em que traz a Organização Administrativa do IFRO, novamente há referência ao NAPNE, informando ser órgão de assessoramento e encontra-se ligado à Reitoria, à Pró-Reitoria de Ensino e, em cada campus, diretamente à Diretoria de Ensino.

Nas Políticas de Atendimento ao Discente, logo após a descrição da finalidade do NAPNE, informa que o NAPNE ainda está em implantação, no âmbito do Instituto Federal de Educação, Ciência e Tecnologia de Rondônia, e suas políticas, devidamente efetivadas por meio de planos, programas e projetos, ainda estão sendo desenvolvidas e deverão ser concretizadas até 2022, em

\footnotetext{
${ }^{8}$ NAPNE - Núcleo de Atendimento às Pessoas com Necessidades Específicas.

${ }^{9}$ PDI aprovado pela Resolução no 29/CONSUP/IFRO de 26/04/2018.
} 
parte ou no todo, quando do término das ações previstas no Plano de Desenvolvimento Institucional.

O IFRO também define, no item Estímulos à Permanência (Programa de Nivelamento, Atendimento Psicopedagógico), ações a serem desenvolvidas por setores específicos no âmbito do Plano Estratégico de Permanência e Êxito, que visa à diminuição dos níveis de evasão e de retenção aos índices minimamente aceitáveis. Ao NAPNE cabe, entre outras, a criação do Grupo de Estudo e Pesquisa em Inclusão - GEPI.

Por último, quanto à infraestrutura física, está o Plano de Promoção de Acessibilidade e de Atendimento Diferenciado a Pessoas com Necessidades Específicas, que inclui Acessibilidade Física (construção, adequação e reforma) e Acessibilidade Educacional, com a proposta de criar um manual padronizado dos ambientes do Instituto Federal de Rondônia, elaborando, a partir deste, um diagnóstico de acessibilidade física que forneça o suporte adequado na elaboração de novos projetos de infraestrutura de acesso aos campi.

\section{Nordeste: Instituto Federal de Alagoas - IFAL ${ }^{10}$.}

A criação do Instituto Federal de Alagoas, em 2008, integrou a Escola Agrotécnica Federal de Satuba, criado como Patronato Agrícola de Alagoas, em 1911, e o Centro Federal de Educação Tecnológica. Atualmente, o IFAL possui 16 campi distribuídos pelo Estado, além da Reitoria, localizada em Maceió.

Logo de início, o Projeto Político-Pedagógico (PPP) informa que as políticas de ensino se constituem em desafios teórico, conceitual e metodológico. As Diretrizes Gerais do Instituto enfatizam a necessidade de garantia de padrões de infraestrutura física e de equipamentos dos Campi e dos Polos do IFAL, inclusive, relativos à acessibilidade de pessoas com deficiências, ampliando, adequando e modernizando laboratórios, salas de aulas, bibliotecas e demais espaços físicos. Isso significa promover o acesso das minorias ao IFAL, contemplando as peculiaridades das pessoas com deficiência e com necessidades educacionais específicas.

Observa-se que as políticas estudantis devem ser direcionadas à permanência com qualidade dos estudantes, na perspectiva da inclusão social. Neste Instituto, existem diversos dispositivos que orientam a atuação de programas e apoio para a educação inclusiva, como: o Plano Estratégico Institucional de Permanência e Êxito (PEIPE); o Fórum Permanente de Assistência Estudantil (FORPAE); os núcleos de ações afirmativas (NAPNE e NEABI) e a Política de Assistência Estudantil (PAE), que compreende, ainda, a educação inclusiva e o protagonismo e organização estudantil. 
Nas políticas estudantis, especificamente com relação à educação inclusiva, o IFAL define como objetivo das políticas de inclusão e acessibilidade a garantia de processos educativos que possibilitem condições equânimes, que abarquem desde o ingresso até a conclusão do curso, tendo como princípio o compromisso com a inclusão e com a acessibilidade, e, entre as diretrizes, a acessibilidade na arquitetura, nos transportes, nos mobiliários, equipamentos, nas comunicações, nos recursos didáticos e pedagógicos. Entre os Programas Universais, o destaque vai para o PAENE - Programa de Assistência às/aos Estudantes com Necessidades Específicas, vinculado ao NAPNE de cada Campus.

Sobre as Políticas de Gestão, destaca-se a Promoção da acessibilidade, que significa atender a toda comunidade, usuários e servidores, incluindo o atendimento prioritário, imediato e diferenciado às pessoas portadoras de necessidades educacionais especiais ou com mobilidade reduzida, para utilização, com segurança e autonomia, total ou assistida, dos espaços, mobiliários e equipamentos urbanos, das edificações, dos serviços de transporte, dos dispositivos, sistemas e meios de comunicação e informação, permitindo a inclusão e o desenvolvimento das atividades fins da Instituição.

\section{Sudeste: Colégio Pedro II - CPII ${ }^{11}$.}

Fundado em 02 de dezembro de 1837, o Colégio Pedro II foi equiparado aos Institutos Federais de Educação, Ciência e Tecnologia com a sanção da lei 12.677/12 e conta, atualmente, com 13.119 alunos matriculados nos 14 campi, sendo 12 no município do Rio de Janeiro, 01 em Niterói e 01 em Duque de Caxias, e no Centro de Referência em Educação Infantil - CREIR, localizado em Realengo.

Na Pró-Reitoria de Ensino - PROEN, onde fica a Coordenação de Cursos de Educação Especial, um dos objetivos específicos prevê reforçar e universalizar a cultura da inclusão, tornando natural a presença de pessoas com necessidades específicas. No CPII, o NAPNE, que engloba os espaços-tempos da Sala de Recursos Multifuncionais e do Laboratório de Aprendizagem, está localizado nos espaços de extensão e complementação pedagógica.

Em duas, das três Diretrizes Estruturantes do Planejamento Institucional, há objetivos estratégicos relacionados à inclusão e acessibilidade, são elas: Acadêmica e Pedagógica, que visa proporcionar o acompanhamento adequado aos discentes com necessidades específicas; e a Gestão e Desenvolvimento, que visa adequar os ambientes pedagógicos e administrativos no sentido de promover o acesso, a circulação e permanência de pessoas com necessidades especiais

${ }^{11}$ PDI aprovado pela Resolução no 147 de 11/09/2019. 
ou mobilidade reduzida. Também, no Plano de Metas (2019-2023), estão previstas obras de acessibilidade em diversos espaços e campi, a depender de liberação de recursos e licitação.

\subsection{Educação Infantil no CPII.}

Em dezembro de 2013, foi criada a Unidade de Educação Infantil Realengo para cumprir, exclusivamente, essa etapa do ensino, iniciada um ano antes no Campus Realengo I. No ano de 2016, foi transformada em Centro de Referência em Educação Infantil Realengo (CREIR), com administração independente do Campus Realengo I, vinculada diretamente à Reitoria.

Para além da inclusão da educação infantil do Colégio, após sua integração à Rede Federal de Educação Profissional, Científica e Tecnológica, o que se destaca aqui é a criação de um NAPNE exclusivo para essa etapa de ensino. O Núcleo na Educação Infantil do Colégio Pedro II começou a ser criado em junho de 2017, sob a orientação da Coordenação Setorial do CREIR e NAPNE Geral/ Diretoria de Assuntos Estudantis - DAE. A Coordenadora do NAPNE/CREIR destaca que "o fato de que a EI ainda não tinha um núcleo voltado às crianças com necessidades educacionais específicas, não significou que estas não eram atendidas em suas singularidades" (FERREIRA e KELMER, p. 07, 2019).

No entanto, a criação de um NAPNE específico, considerando as especificidades da faixa etária atendida (3 a 6 anos), com todas as exigências de formação dos profissionais e as competências definidas pelo Atendimento Educacional Especializado (AEE), estaria inovando em respeito ao atendimento em educação especial desde a educação infantil, que no CPII, caracterizase também pela bidocência, que corresponde a ter dois professores por turma.

\section{Sul: Instituto Federal Farroupilha - IFFAR ${ }^{12}$.}

O Instituto Federal de Educação, Ciência e Tecnologia Farroupilha - IFFAR nasceu, em 2008, da integração entre 4 instituições: o Centro Federal de Educação Tecnológica de São Vicente do Sul, a unidade Descentralizada de Júlio de Castilhos, a Escola Agrotécnica Federal de Alegrete e a unidade Descentralizada de Ensino de Santo Augusto, que anteriormente pertencia ao Centro Federal de Educação Tecnológica de Bento Gonçalves.

As ações e propostas para atendimento de estudantes com necessidades específicas do PDI 2019-2026, do IFFAR, iniciam pela meta de tornar 100\% da estrutura física condizente com as questões de acessibilidade e inclusão. É importante destacar que o IFFAR conta, em todos os campi e na Reitoria, com a Coordenação de Ações Inclusivas ${ }^{13}$ (CAI), cujas ações e projetos

\footnotetext{
${ }^{12}$ PDI aprovado pela Resolução CONSUP n ${ }^{\circ} 009$ de 26/04/2019
}

${ }^{13}$ Resolução CONSUP no $15 / 2014$ 
buscam garantir condições e oportunidades educacionais igualitárias e correta execução da Política de Diversidade e Inclusão da entidade.

A institucionalização das ações do IFFAR ensejou uma série de documentos, entre os quais citamos Regimento da Coordenação de Ações Inclusivas; Política de Diversidade e Inclusão; Regulamento do Núcleo de Elaboração e Adaptação de Materiais Didático/Pedagógico; Regulamento de Atendimento Educacional Especializado; Política de Ações Afirmativas de Inclusão Socioeconômica, Étnico-Racial e para PcD; Manual de Procedimentos Acessíveis para Processos Seletivos; Regulamento de Terminalidade Específica e Plano de Acessibilidade Arquitetônica e Estrutural.

Entre os princípios da Política de Diversidade e Inclusão do IFFAR, presentes nos citados documentos, são mencionados o convívio e respeito às diversidades étnica, cultural, social, sexual, de gênero, de crença, de necessidades específicas ou outras características individuais, coletivas e sociais, e promoção à acessibilidade.

Destaque para dois dos Núcleos Inclusivos: Núcleo de Apoio às Pessoas com Necessidades Específicas (NAPNE), já implementado em cada um dos campi e o Núcleo de Elaboração e Adaptação de Materiais Didáticos/Pedagógicos do IFFAR (NEAMA), cuja função é dar suporte a todos os campi na elaboração de materiais didáticos/pedagógicos adaptados. $\mathrm{O}$ NEAMA está alocado na Reitoria, e inclui revisores de Texto Braille, tradutores intérpretes de Libras e demais profissionais necessários para produção e adaptação de materiais didáticopedagógicos.

Com relação à infraestrutura, o PDI do IFFAR destaca que a instituição prioriza a inclusão entre alunos, professores, funcionários e a comunidade em geral, melhorando constantemente a infraestrutura de acessibilidade com a inclusão de projetos de acessibilidade para todas as obras novas e reformas.

\section{Centro-Oeste: Instituto Federal de Mato Grosso do Sul - IFMS $^{14}$.}

A Lei $n^{\circ} 11.534$, de 25 de outubro de 2007, criou 02 escolas técnicas e agrotécnicas federais em Mato Grosso do Sul, nas cidades de Campo Grande e Nova Andradina. No ano seguinte, com a reestruturação da Rede Federal, foi criado o IFMS prevendo a instalação dos campi nos mesmos municípios. Com os projetos de expansão da Rede Federal, que se seguiram, o IFMS possui atualmente 10 Campi, que atendem todas as regiões do estado.

As questões relativas à inclusão, acessibilidade e de atendimento diferenciado a pessoas com deficiência, no PDI, são abordadas no item 'Políticas de Gestão', que cita o NAPNE como

${ }^{14}$ PDI aprovado pela Resolução no 067/CONSUP de 13/12/2018. 
uma prática de inclusão dentro da promoção dos direitos humanos, tendo como finalidades propor normas de inclusão a serem praticadas na instituição, promover a temática da acessibilidade em todas as suas acepções, bem como prestar atendimento aos estudantes com necessidades educacionais específicas.

Considerando a inclusão social de todos os grupos um desafio institucional, o IFMS planeja instituir, durante a vigência do atual PDI, a Política de Responsabilidade Social, que incluirá, entre outras ações, o Plano de Promoção da Acessibilidade e de Atendimento Diferenciado a Pessoas com Deficiência ou Mobilidade Reduzida. Entre as ações desenvolvidas pelo Instituto como parte da responsabilidade Social, incluem-se o NAPNE e a promoção de acessibilidade comunicacional, arquitetônica, atitudinal, metodológica, entre outras, para estudantes, servidores e comunidade externa, articulada pela Coordenação de Inclusão e Diversidade.

No Plano de Metas, o macro objetivo intenta promover a inclusão social, acessibilidade e respeito à diversidade, tendo entre as metas adequar a infraestrutura física e tecnológica para garantia da acessibilidade e promoção do esporte, elaborar e implementar o Plano de Promoção da Acessibilidade e de Atendimento Diferenciado a Pessoas com Deficiência ou Mobilidade Reduzida e implantar o uso de tecnologias em processos educacionais para facilitar a acessibilidade e o atendimento diferenciado a pessoas com deficiência ou mobilidade reduzida.

Entre as políticas de atendimento aos discentes, as ações de inclusão e diversidade, visam incluir os estudantes nas atividades institucionais, objetivando oportunidades iguais de acesso e permanência às pessoas com necessidades educacionais específicas e também contemplam diferenças de classe social, gênero, idade e origem étnica. O NAPNE é uma dessas ações. Na descrição da Infraestrutura do Instituto, o PDI /IFMS foi o único a incluir as vagas de Estacionamento para $\mathrm{PcD}$, disponíveis em cada campus.

\section{CONSIDERAÇÕES FINAIS}

Os resultados apresentados neste capítulo não permitem 'fechar' questão em torno dos itens destacados. Antes, pressupõem uma série de condicionalidades, propósitos e intencionalidades que indicam a busca por promover inclusão, autonomia, melhoria da qualidade de vida, inserção social e, sobretudo, o acesso à educação com permanência e sucesso na aprendizagem. Ou seja, tudo o que está garantido sob o ponto de vista do direito à educação, em termos legais, porém em estágios diferentes nas condições de oferta, conforme o PDI de cada um dos cinco Institutos. 
É preciso reconhecer que avançamos conceitualmente, como também é urgente reconhecer que a prática precisa incorporar essas discussões e avanços para além da acessibilidade arquitetônica, oferecendo condições para que os estudantes com deficiência e/ou com necessidades específicas, sintam-se não somente incluídos, como respeitados nas suas especificidades.

Se a inclusão é um processo ainda não consolidado em sua totalidade, a análise dos Planos de Desenvolvimento Institucional demonstra que os espaços têm sido ocupados e ampliados com políticas e ações que definem novos rumos para a educação especial, apesar do contingenciamento financeiro e da redução das políticas de educação especial no último ano.

\section{REFERÊNCIAS}

COLÉGIO PEDRO II- CPII. Plano de Desenvolvimento Institucional. Disponível em: https://www.cp2.g12.br/. Acesso: 10/02/2020.

FERREIRA, Cintia Tavares; KELMAN Celeste Azulay. A construção de um NAPNE na Educação Infantil do Colégio Pedro II. In: WESSELOVICZ, Glaucia; CAZINI Janaína (Orgs.) Diálogos sobre Inclusão. Atena Editora, 2019. Disponível em: https://pt.slideshare.net/Antonella0611/dilogos-sobre-incluso-2 Acesso: 06/02/2020

INSTITUTO NACIONAL DE ESTUDOS E PESQUISAS EDUCACIONAIS ANÍSIO TEIXEIRA/INEP - Sinopse Estatística da Educação Superior 2011 a 2018. Brasília: Inep, 2019. Disponível em: http://portal.inep.gov.br/basica-censo-escolar-sinopse-sinopse Acesso em: 02/02/2020.

Sinopse Estatística da Educação Básica 2018. Brasília: Inep, 2019. Disponível em: $\overline{\mathrm{http}} / / /$ portal.inep.gov.br/sinopses-estatisticas-da-ediucacao-basica Acesso: 02/02/2020.

IBGE. Metodologia do Centro Demográfico 2000. Rio de Janeiro: IBGE, 2003. (Série Relatórios Metodológicos 25). Disponível em: http://goo.gl/UvlwF. Acesso: 08/02/2020.

INSTITUTO FEDERAL DE ALAGOAS - IFAL. Plano de Desenvolvimento Institucional. Disponível em: https://www2.ifal.edu.br/. Acesso: 10/02/2020.

INSTITUTO FEDERAL FARROUPILHA - IFFAR. Plano de Desenvolvimento Institucional. 2019-2023. Disponível em: https://www.iffarroupilha.edu.br/. Acesso: 11/02/2020.

INSTITUTO FEDERAL DO MATO GROSSO DO SUL - IFMS. Plano de Desenvolvimento Institucional. Disponível em: https://www.ifms.edu.br/. Acesso: 11/02/2020.

INSTITUTO FEDERAL DE RONDÔNIA - IFRO. Plano de Desenvolvimento Institucional. Disponível em: https://portal.ifro.edu.br/. Acesso: 10/02/2020.

MARCELINO, M. A. Capacitação de multiplicadores. INSS, Brasília: 2013.

Disponível em: https://peritomed.files.wordpress.com/2013/12/1-a-evolue7e3o-do-conceito-dedeficieancia-capacitae7e3o-lei-compl-142-2013.pdf. Acesso: 08/02/2020. 
MAZZOTTA, M. J. S. Educação especial no Brasil: história e políticas públicas. 5 ed. São Paulo: Cortez, 2005.

MURIEL. R. Plano de Desenvolvimento Institucional - PDI - Análise do processo de implementação. Espírito Santo: Editora Hoper, 2006.

ROCHA, Vânia M. A educação especial nos institutos federais: o que dizem os Planos de Desenvolvimento Institucionais? 2016. Dissertação (Mestrado em Educação) - Universidade da Região de Joinville. Joinville, 2016.2 Disponível em: <https://www.univille.edu.br/account/mestradoedu/VirtualDisk.html/downloadDirect/1078176/ RO> Acesso: 12/02/2020.

SASSAKI, Romeu K. Inclusão: construindo uma sociedade para todos. Rio de janeiro: WVA editora, 1999.

SANTOS, Y. B. S. As políticas públicas de educação para a pessoa com deficiência: a proposta desenvolvida nos Institutos Federais de Educação, Ciência e Tecnologia. Dissertação (Mestrado em Educação) - Universidade Federal do Ceará, Fortaleza, 2011. Disponível em: http://www.repositorio.ufc.br/handle/riufc/3038 Acesso: 02/02/2020. 